\title{
Record Authenticity as a Measure of Trust: A View Across Records Professions, Sectors, and Legal Systems
}

\author{
Corinne Rogers \\ University of British Columbia \\ Vancouver, Canada \\ cmrogers@mail.ubc.ca
}

\section{Summary}

The ability to assess and protect the authenticity of records is axiomatic to archival science, and enjoys a centuries' long theoretical foundation. This paper presents a summary of the author's research into contemporary ideas about authenticity of digital records among records professionals. It found that the issue of authenticity is as much social as technical, with records professionals using social indicators over technical ones in managing authenticity, but relying on technical means to authenticate records. It presents the role of legal system as an independent variable in considerations of authenticity, opening up a line of inquiry for further study.

Keywords: Authenticity, Trustworthiness, Juridical system, Indicators of authenticity

\section{Introduction}

The ability to assess and protect the authenticity of records is axiomatic to archival science, and enjoys a centuries' long theoretical foundation. Authenticity is frequently identified by records professionals as a requirement, or a goal, when creating and preserving the records upon which modern society relies. Beyond that goal, however, identifying the attributes required to make an attestation of authenticity, or the conditions upon which authenticity can be assessed or presumed, is neither easy nor standardized. In this paper I will present a summary of research into contemporary ideas about authenticity of records and data, and practices employed in its service by records professionals - those entrusted both with managing current digital information, and preserving information no longer used by its original creator.

\section{Background}

Two aspects of records research that permeate archival discourse regardless of juridical system are the determination and maintenance of authenticity. The concept of documentary authenticity has ancient roots. The word authenticity 
derives from the Anglo-Norman, Old and Middle French, with reference to a thing (as a noun, authenticum, originally and frequently a legal document), or a person (as an adjective, denoting trustworthy, credible, genuine, or legally or duly qualified). Its etymon is the Latin authenticus, referring to documents (2nd century a.d.), persons (3rd century a.d.), and later coming to mean something or someone who is authoritative (from 8th century in British sources), or a thing

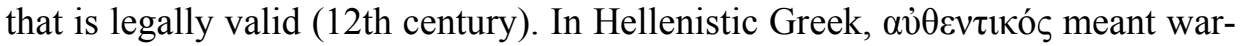
ranted, original, authoritative (Oxford English Dictionary 2014).

Record authenticity today is mandated in standards for records management and preservation frameworks such as ISO 15489:2001 and OAIS - Open Archival Information Systems (International Standards Organization 2001; CCSDS 2012), and the protection of authenticity is required by professional codes of conduct (cf. SAA 2011; ACA 1999). Although theoretical frameworks have been proposed for the protection of authenticity - some of them highly influential in practice, for example in the development of the DoD 5015.2 standard for records management systems (Duranti and MacNeil 1997) and in the development of Italian legislation (this research, Interview subject D073)), despite the wealth of past and current research, establishing and guaranteeing authenticity are still discussed as urgent problems yet to be solved. In the digital environment, research agendas in the information management communities focus on authenticity as an integral value that must be protected over time and across technological change through digital preservation (joining values of sustainability, accessibility, and understandability), broadening the scope of enquiry beyond records as defined by archival theory to include documents, data, and digital objects of all types.

Sir Hilary Jenkinson believed that archival documents (i.e. records) were "authenticated by the fact of their official preservation" (Jenkinson 1937, 4). To Jenkinson, records' history of legitimate custody alone, then, was a sufficient predictor and guarantor of the trustworthiness of the material. Michael Cook, writing 50 years later, dismissed Jenkinson's absolute faith in the documentary chain of custody (or perhaps the assumption that such chain of custody can be presumed or demonstrated) (Cook 1986, 129). Thus, archival institutions cannot trust the records they intend to acquire solely on the basis of their custodial history, but must test them for indications of their authenticity through studying their provenance and elements of their form (diplomatics) (Cook 1986, 7).

Today, digital technology has changed the way we communicate, conduct business, present our public face(s), and document our private lives. Digital culture is challenging the viability and legitimacy of many well-established social and cultural norms and their associated legal frameworks (Doueihi 2011, 12). One aspect of this evolution can be observed in our concepts of trust in digital information, our re-conception of what it means for a digital object to be authentic, and how we can assess its authenticity. "Virtual authenticity is not to be explained by a transfer of a well-known and ultimately problematic category from 
one model to another; it is not to be restricted to a shift from the real to the virtual" (Doueihi 2011, 53).

\section{Hypothesis and Research Questions}

The hypothesis of this study is that, despite clear guidance offered by archival science on the means of ensuring, managing, and continuously assessing record authenticity, a guidance reflected in the products of several large-scale, significant and influential research projects on the topic of authenticity in the context of long-term preservation, the theoretical results of these projects are not being consistently applied in practice, and in fact records professionals are often unclear about how to define authenticity, how to protect it, and how to assess it (authenticate records). This research explores the practices, experience, and beliefs of records professionals. The primary purpose is to further our understanding of how these professionals, primarily but not exclusively archivists and records managers 1 , think about authenticity of the digital material for which they are responsible, and of what techniques or indicators of authenticity they use and rely on to ensure or continuously assess it. This study asks three broad research questions (the first two of which are discussed below) in order to investigate the convergence of theory and practice in the matter of establishing, maintaining, and assessing authenticity of digital records and data:

- Research Question 1: What elements of the context, content, and structure of digital records and data (indicators of authenticity) do records professionals use and rely on most to determine and manage authenticity?

- Research question 2: Do records professionals rely on the traditional archival model of record authenticity in the digital environment and if so, to what degree?

- Research question 3: Do records professionals consider the traditional archival model of authenticity sufficient to support a presumption of authenticity in the digital environment over time and across technological change?

\section{Methodology}

This research is grounded first and foremost in the theory and methodology of archival science and diplomatics, which provide a model of "record", and a means of understanding and defining record authenticity as well as the elements that comprise it. This model traces its origins to 17 th century diplomatics, if not archival practice dating back as far as the Roman Empire and documented in the

\footnotetext{
${ }^{1}$ The distinction, perceived or real, between records managers and archivists, has been much discussed, and different national traditions view them as parts of one unified profession or two distinct ones. In formulating the research questions, I focused on the practice of records professional broadly - that is, any professional concerned with the nature of records and the establishment of their authenticity.
} 
Justinian Code (Duranti 1998a, 36-40). It was further developed and tested for the digital environment through the research of the InterPARES Project. A record is defined as a document made or received in the course of practical activity and set aside for future action or reference. Authenticity is assessed by establishing its identity and demonstrating its integrity. In the digital environment a presumption of authenticity is an inference based on evidence about how the records have been created and maintained. Evidence may come from the records creator, or through further analysis to verify authenticity, such as comparison of the records with copies preserved elsewhere (redundancy), forensic analysis, testimony of a third party, or analysis of audit trails (MacNeil and GillilandSwetland 2005; Duranti 2005; Duranti and Thibodeau 2006; Duranti and Preston 2008).

This study used both quantitative and qualitative methods of data collection and analysis. Quantitative and qualitative data were collected through a questionnaire consisting of closed and open questions, circulated online through major English-speaking archival and records management listservs. Further qualitative data were collected through semi-structured interviews with selected respondents based on questions arising from the answers to the questionnaire.

The questionnaire was designed to measure practitioners' notions of authenticity of digital records and data and explore the relationship between practice and belief among records professionals - that is, what records professionals rely on in their work and whether their practice matches their belief or trust in specific authenticity indicators. Questions gathered basic information about the extent to which records professionals are concerned about the authenticity of digital records and data, how they ensure, assess, and/or protect it, and the level of importance that they place on specific indicators of authenticity.

\section{Selected Results}

The questionnaire was posted online from March 3-May 1, 2014 and reached professionals in 46 different countries or territories on six continents. Two hundred and ninety-three completed responses were received from archivists $(\mathrm{n}=134)$, records managers $(\mathrm{n}=97)$, and other $(\mathrm{n}=62)$, employed in government/industry $(n=139)$ or cultural heritage institutions $(n=158)$. Responses were received from civil law jurisdictions $(n=64)$, common law jurisdictions $(n=215)$, and pluralistic or religious law jurisdictions $(\mathrm{n}=14)$.

The main focus of the questionnaire was to explore the relationship among practice, experience, and belief with respect to the use of and value placed on a set of indicators of authenticity. The proposed indicators are based on the English-language archival literature, and categorized as social (S) or technological (T) (Table 1). 
Table 1. Indicators of authenticity

\begin{tabular}{|l|}
\hline Social indicators \\
\hline \\
Written policies and procedures governing the management of the records system \\
\hline Documentation about the record system (design, operation, management, etc.) \\
\hline Written policies and procedures governing digital records \\
\hline Classification scheme and/or file plan \\
\hline Retention and disposition schedules \\
\hline Archival description \\
\hline Technical indicators \\
\hline \begin{tabular}{l} 
Information about the software used to create and manage the digital records \\
\hline Information about changes made to the digital records over time, (e.g. migration, normali- \\
\hline zation, etc.)
\end{tabular} \\
\hline Information about actions taken to preserve the digital records \\
\hline Access controls/security measures \\
\hline Audit logs \\
\hline Cryptographic validation techniques (e.g. digital signatures, hash digests, etc.) \\
\hline Standardized metadata \\
\hline
\end{tabular}

Social indicators are instruments developed by an organization to support the creation, management, or preservation of records (e.g. classification schemes, retention and disposition plans, policies and procedures documents). They are based on domain knowledge, and created and implemented by the intention of human actors (records professionals, management, legal counsel, etc.). They may or may not be present within a given organization; they may be mandatory or voluntary in their application or use, and even when mandatory, they may be circumvented or adapted, as Foscarini showed in her study of central banks (Foscarini 2009). They include the foundational instruments of archival and records management practice: policy instruments, classification schemes or file plans, retention and disposition schedules, and archival description or other descriptive measures (which may be captured in varieties of descriptive metadata). Technical indicators are non-discretionary in their creation - that is, they are the result of a work process or state change in the records (e.g. system metadata capturing date created, and date modified), are algorithmically generated or implemented by the technological (e.g. computer, network) components of the overall record system (e.g. checksums, audit logs), are created to manage and control system access and security, or are created by a third party as specifications to a part of the technological system (e.g. documentation about software). Technological indicators may be used to control the records, but are more focused on controlling the system in which the records reside. They include audit logs, access controls and security measures, cryptographic validation techniques, and system metadata, as well as technical documentation.

Questions measured who used different indicators most or least in the course of their normal work to ensure authenticity, how these indicators were used in the event of a formal attestation of authenticity, what indicators practitioners be- 
lieved to be most important in attesting to authenticity, and how frequently social versus technical indicators were invoked in use and in belief.

A key distinction between respondents is whether or not they have been required to make a formal attestation of authenticity in the course of their work. This allows a determination of whether work practice differs between those who have, and those who have not been required to authenticate a body of records. The differences between beliefs and practice is also explored by asking respondents who had not ever had to authenticate records what they think they would use if required to authenticate records.

Several themes emerged from the questionnaire that supported the research questions, and warranted further investigation through interviews. These were:

- the difference between practice and belief of records professionals regarding different indicators for ensuring or assessing authenticity,

- the relative weight of technical versus social factors in ensuring or assessing authenticity either in practice or belief, and

- the role of experience in making attestations of authenticity in practice and belief.

Furthermore, the interviews provided an opportunity to ask specific questions about the role, if any, of the system of law (civil or common law), and the extent to which traditional archival models of authenticity suffice in the digital environment. The results of the questionnaire were confirmed in 17 interviews (Table 2).

Table 2. Interviewees

\begin{tabular}{|l|l|l|}
\hline & Government/Industry & Cultural heritage \\
\hline Civil law (n=6) & Records managers -4 & Archivists -2 \\
\hline Common law (n=11) & Records managers -1 & Records managers -2 \\
\hline & Archivists -2 & Archivists -3 \\
\hline & Other -1 & Other -2 \\
\hline
\end{tabular}

\section{Role of legal system}

It is interesting that in the questionnaire sample there was no statistical difference among professionals working in different legal systems based on the questions asked. In what way might a country's system of law influence the work of archivists and records managers in establishing and assessing record authenticity? The roots of archival theory and concepts of record authenticity are anchored in legal and administrative principles, first executed in centralized public repositories of written documents, then, with the spread of literacy, expanding into the regulated recordkeeping practices of public and private organizations, administrations, and homes (Eastwood 1994, 125; Duranti 1998b). Law and jurisprudence are the original pillars of influence that have guided the history and development of archival theory, reaching back through the centuries to Roman times. Principles from Roman law that have become part of the founda- 
tion of archival knowledge include the idea that antiquity provides records with the highest legal authority, that deposit in a public place guarantees reliability of records as witnesses of actions, and that an unbroken chain of custody ensures records' continuing authenticity (Duranti 1996, 1).

The international records management standard, ISO 15489, is recognized in civil and common law systems. The idea of record authenticity is codified in ISO 15489 as follows: "An authentic record is one that can be proven to be what it purports to be, to have been created or sent by the person purported to have created or sent it, and to have been created or sent at the time purported" (International Standards Organization 2001 section 7.2.2). These concepts are explicated in domain distinctions among history, jurisprudence, and diplomatics - namely, the objects of authenticity inquiry (primary source material, works of art, legal instruments, records, etc.) that are important to historians, legal professionals, and archivists. For the purposes of understanding and analyzing documents and records, Duranti has differentiated among three types of authenticity: diplomatic, legal, and historical. Each is distinct and independent from the other, and reflects a specific purpose or focus of trust and the trust relationship in its discipline. Legally authentic documents bear witness on their own because of the intervention, during or after their creation, of a representative of a public authority guaranteeing their genuineness. Diplomatically authentic documents are those that were written according to the practice of the time and place indicated in the text, and signed with the name(s) of the person(s) competent to create them. Historically authentic documents attest to events that actually took place or to information that is true (Duranti 1998a, 45-46). An authentic document is conditioned by the discipline in which it is considered - and therefore the purpose the document serves. This holds regardless of legal system, although it may be expressed in different ways.

The system of law of many countries has developed out of one of two traditions - the English common law and the French civil law. These systems have spread through conquest and colonization throughout the world, common law transplanted to the United States, Canada, Australia, New Zealand, and parts of Asia and Africa and civil law to much of Europe, Latin America, and parts of Asia and Africa. Although there are differences in each tradition among different countries, in general the distinction can be summarized as follows: civil law systems utilize professional judges, legal codes and written records, while common law systems rely on lay judges, broader legal principles, and oral arguments (Glaeser and Shleifer 2002, 1196-1197).

In common law systems, authenticity is part of the foundation upon which the admissibility of documentary and real evidence is based, proven through the authentication of documents at the moment they are introduced as evidence. Authentication of documentary evidence can be proven through testimony, expert analysis, non-expert opinion, or, in the case of public documents or other special types, circumstances of record creation and preservation. 
Traditionally, documentary evidence should be "best evidence", satisfied by production of an original. Authentication serves to establish the identity of the record and its relevance to the issues in the proceeding, while the best evidence rule demands proof of the integrity of the contents (MacNeil 2000, 46-48). However, the historical notion of authenticity, whereby an authentic record is one which attests "to events that actually took place or to information that is true" (Duranti 1998a, 46), focuses attention on the contents of a document and their truthfulness. Mapped to legal practice, historical authenticity is seen in moments when a document is considered "for the truth of its contents" (Sheppard and Duranti 2010, 27). This is tested not through authentication or establishment of best evidence, but in the consideration of the hearsay nature of the document, and is linked to reliability.

Some interviewees found solid legislative support for recordkeeping, while others noted a failure to keep up with technological advances. One interviewee in New Zealand noted that there is a high-level legislative regulatory apparatus for designing systems in the public sector, and guidance at a more granular level for recordkeeping systems in ISO 1617 Part 2. A template for writing records policy, and a metadata standard with technical requirements and a schema provide additional support. This provides a good basic framework to work from and test the systems against minimum requirements. In Australia, the UK, the US, and New Zealand standards assess and accredit recordkeeping systems from vendors, but throughout the 2000s this became increasingly untenable. The situation is more complicated in the UK and North America, where legislation regulating records generally does not address record authenticity specifically.

Civil law systems require a greater measure of procedural formalism than common law systems in regulating dispute resolution through bright line rules for collection and presentation of evidence (Djankov et al. 2002, 37). This can result in extremely detailed and prescriptive rules governing the creation of records of public administrations. For example, in Italy the attention of records professionals when designing systems for management and storage of records is focused on the implementation of national legislation which dictates a rich set of metadata establishing identity and integrity, supported by documentation about policies and procedures outlining clear responsibilities. Italian legislators have recently provided detailed guidelines to verify the quality of metadata and applications for records creation and (as a consequence) for their transfer to any kind of custodial environment (including cloud storage). Specific attention is paid to the documentation and metadata provided for transferring records from the creator environment to any other system (Interviewee D037).

Interviewees were asked if specific laws governed their work, based on the national system of law in which they worked. I wanted to understand from them whether there was a difference in the framework supporting authenticity of records between common law and civil law countries. I hypothesized that there would be a clear difference, but this was not the case. The legislative framework 
in Italy has already been introduced. General legislation clarifies the minimum amount of metadata required for identity and integrity, including classification, reference code obligations, and specific rules for records management systems. Information related to provenance, identity, and context must be well defined and must be written and exchanged according to specific rules. The interviewee noted strong cooperation in Italy between archivists, records managers, and legislators. However, Italy appears to be the exception rather than the rule in civil law countries among the interviewees questioned. In another European civil law jurisdiction interviewees reported that there has been a change over the last six or so years, and today a common trend is to ignore the law and take the path of least resistance. An interviewee from a third civil jurisdiction noted that the regulations that do exist are at a very high level and do not provide any specific guidance.

\section{Limitations and Conclusion}

Web-based surveys conducted through professional listservs are convenient, but they do have limitations, primarily the inability of guaranteeing a representative sample. Individuals self-select to join a listserv and to participate in questionnaires. Results therefore may be practically significant, but as there can be no truly random sample, results may be difficult to generalize, nor can validity be objectively measured. However, as an indicator of general practice, such surveys provide useful information.

This research explored the relationship between practice and belief in establishing and assessing authenticity of digital records among a sample of records professionals. Overall, respondents adopt a pragmatic approach to authenticity based on resources, sensitivity of the records, and organizational or legislative framework. In response to the first two research questions, across variables of profession, sector, and legal system these professionals rely most heavily on social indicators of authenticity in daily work, but exercise greater trust and reliance on technical indicators in the process or expectation of authenticating records. Experience of authenticating records affected belief in the value of indicators, with those who had never had to authenticate records placing higher faith in technical indicators. Interviewees generally agreed that the traditional archival model of record authenticity still held in the digital environment (RQ3), but required adaptation. Although the research did not originally intend to explore in depth the function of legal system as an independent variable, the findings that did emerge open up an interesting line of inquiry for further study. 


\section{References}

ACA. 1999. "Code of Ethics | The Association of Canadian Archivists." http://archivists.ca/ content/code-ethics.

CCSDS. 2012. "Reference Model for an Open Archival Information System (OAIS): Recommended Practice Issue 2." Consultative Committee for Space Data Systems. http://public. ccsds.org/publications/archive/650x0m2.pdf.

Cook, Michael. 1986. The Management of Information from Archives. Aldershot, Hants, England ; Brookfield, Vt., U.S.A: Gower.

Djankov, Simeon, Rafael La Porta, Florencio Lopez-de-Silane, and Andrei Shleifer. 2002. "Courts: The Lex Mundi Project." Working Paper 8890. National Bureau of Economic Research. http://www.nber.org/papers/w8890.

Doueihi, Milad. 2011. Digital Cultures. Cambridge, Massachusetts: Harvard University Press.

Duranti, Luciana. 1996. "Archival Science.” In Encyclopedia of Library and Information Science, 59:1-19. New York, Basel, Hong Kong: Marcel Dekker.

- 1998a. Diplomatics: New Uses for an Old Science. Lanham: Scarecrow Press. $23(3)$.

- 2005. The Long-Term Preservation of Authentic Electronic Records: Findings of the InterPARES Project. San Miniato: Archilab.

Duranti, Luciana, and Heather MacNeil. 1997. "The Preservation of the Integrity of Electronic Records: An Overview of the UBC-MAS Research Project." Archivaria 42 (Spring): 46-67.

Duranti, Luciana, and Randy Preston. 2008. Research on Permanent Authentic Records in Electronic Systems (InterPARES) 2: Experiential. Interactive and Dynamic Records. Padova: Associazione Nazionale Archivistica Italiana.

Duranti, Luciana, and Kenneth Thibodeau. 2006. "The Concept of Record in Interactive, Experiential and Dynamic Environments: The View of InterPARES." Archival Science 6 (1): 13-68.

Eastwood, Terry. 1994. "What Is Archival Theory and Why Is It Important?" Archivaria 37 (Spring): 122-30.

Glaeser, Edward L., and Andrei Shleifer. 2002. "Legal Origins." The Quarterly Journal of Economics 117 (4): 1193-1229. doi:10.1162/003355302320935016.

International Standards Organization. 2001. "ISO-15489 Information and Documentation-Records Management, Part 1, 2.” Text. Geneva: ISO. http://www.iso.org/iso/catalogue_detail? csnumber $=31908$.

Jenkinson, Hilary. 1937. A Manual of Archive Administration. New and Revised. London: Percy Lund, Humphries \& Co. http://www.archive.org/details/manualofarchivea00iljenk.

MacNeil, Heather. 2000. Trusting Records: Legal, Historical, and Diplomatic Perspectives. Dordrecht: Kluwer Academic.

MacNeil, Heather, and Anne Gilliland-Swetland. 2005. "Authenticity Task Force Report.” In The Long-Term Preservation of Authentic Electronic Records: Finding of the InterPARES Project, edited by Luciana Duranti. San Miniato, Italy: Archilab.

Oxford English Dictionary. 2014. "Authentic, Adj. and N." OED Online. Oxford University Press. http://www.oed.com.ezproxy.library.ubc.ca/view/Entry/13314.

SAA. 2011. "SAA Core Values Statement and Code of Ethics." Society of American Archivists. http://www2.archivists.org/statements/saa-core-values-statement-and-code-of-ethics.

Scanlan, Daniel M. 2011. Digital Evidence in Criminal Law. Aurora, Ont.: Canada Law Book.

Sheppard, A. F., and Luciana Duranti. 2010. "The Canadian Legal Framework for Evidence and the Digital Economy: A Disjunction?" SSHRC Knowledge Synthesis and the Digital Economy. University of British Columbia. 